\title{
Prevalence, agreement and classification of various metabolic syndrome criteria among ethnic Chinese: A report on the hospital-based health diagnosis of the adult population
}

\author{
Kuo-Liong Chien ${ }^{\mathrm{a}, *}$, Bai-Chin Lee ${ }^{\mathrm{b}}$, Hsiu-Ching Hsu ${ }^{\mathrm{b}}$, \\ Hung-Ju Lin ${ }^{\mathrm{b}}$, Ming-Fong Chen ${ }^{\mathrm{b}}$, Yuan-Teh Lee ${ }^{\mathrm{b}, \mathrm{c}}$ \\ ${ }^{a}$ Institute of Preventive Medicine, School of Public Health, National Taiwan University, Taiwan \\ ${ }^{\mathrm{b}}$ Department of Internal Medicine, National Taiwan University Hospital, Taipei, Taiwan \\ ${ }^{\mathrm{c}}$ Ming-Shen Medical Center, Taoyuang, Taiwan
}

Received 20 July 2006; received in revised form 19 December 2006; accepted 9 January 2007

Available online 8 February 2007

\begin{abstract}
Objectives: Many criteria of metabolic syndrome have been made available to practitioners in the recent past. This study has been designed to investigate the distribution, agreement and classification patterns of these criteria among the ethnic Chinese population.

Methods: A total of 6610 (women, 42.5\%) adults (mean, 52.3 years) were recruited from the hospital-based health diagnosis program during 2004. We divided criteria of metabolic syndrome into two groups: those with a major component required (WHO, EGIR, AACE, IDF) and those with equal component (ATP III, AHA, with modifications).

Results: The highest standardized rates were in Asian AHA criterion, up to $29.8 \%$ in men and $25.6 \%$ in women. The lowest rates were in WHO criterion, $8.8 \%$ in men and $8.0 \%$ in women. The $\kappa$ values using all criteria were 0.59 in men and 0.65 in women and decreased in the major component group ( 0.50 in men, 0.54 in women), while increased in the equal component group ( 0.83 in men, 0.81 in women). Using hierarchical cluster analysis and dendrograms, two large clusters were identified in men (major components and equal components); however, mixed sub-clusters of major and equal components apparently grouped by insulin resistance and obesity criteria in women.

Conclusions: There is substantial agreement and grouping of metabolic syndrome models among ethnic Chinese.
\end{abstract}

(C) 2007 Elsevier Ireland Ltd. All rights reserved.

Keywords: Metabolic syndrome; Cross-sectional study; Agreement; Classification

\section{Introduction}

Metabolic syndromes have placed a great burden on public health and clinical practice [1], and their high prevalence and impact on atherosclerotic risk are proven among different ethnic populations [2-4]. Also, many criteria for metabolic syndrome have been made available in the recent past. These criteria have also been classified into two groups. One group

\footnotetext{
* Corresponding author at: Institute of Preventive Medicine, College of Public Health, National Taiwan University, Room 517, No. 17, Hsu-Chou Road, Taipei 100, Taiwan. Tel.: +886 23322 8017; fax: +886223920456.

E-mail address: klchien@ha.mc.ntu.edu.tw (K.-L. Chien).
}

emphasizes one major criteria, including insulin resistance or central obesity, plus other atherosclerotic components. It includes definitions from the World Health Organization (WHO) [5], the European Group for Study of Insulin Resistance (EGIR) [6], American Association of Clinical Endocrinologists (AACE) [7] and the International Diabetes Federation (IDF) [8]. The other group treats all atherosclerotic risk components equal, defining metabolic syndrome if there are more than or equal to three components of high blood pressure, dyslipidemia, obesity and hyperglycemia. It includes definitions from the National Cholesterol Education Program (NCEP) Adult Treatment Panel III (ATP III) [9] and the American Heart Association/National Heart, 
Lung, and Blood Institute (AHA/NHLBI) criteria [10]. Ethnic variations in obesity definition for central obesity by waist circumference and general obesity by body mass index (BMI) roles introduced complications [11]. Consensus on metabolic syndrome definitions and clinical implications are still arguable $[12,13]$. The above various criteria confuse health professionals, especially in non-Caucasian populations, such as with ethnic Chinese [14,15]. First, we do not know the consistency and agreement among the above criteria and potential influence of each criterion. Second, the underlying groups or clusters of metabolic syndrome models are unknown. Although previous analytic techniques such as factor analysis and classification methods have been applied in clarifying the dimensions of metabolic syndrome components $[16,17]$, there are no available reports on the consistency and grouping of various criteria.

This study explored the complexity of different metabolic syndrome criteria in the ethnic adult Chinese population. First, we estimated the age standardized prevalence rates; then quantified the degree of agreement among available metabolic syndrome criteria. We identified the influence of specific criterion of metabolic syndromes and classified these criteria by their similarity, grouping into several sub-clusters among ethnic Chinese.

\section{Methods}

\subsection{Study design and population}

The study design was a cross-sectional study and the 6610 adult (women: $42.6 \%$ ) participants were recruited from the Health Management Center of one tertiary hospital from January 2004 to December 2004. Details of socioeconomic status, along with medical and medication histories were collected by questionnaires, and standardized clinical procedures were undertaken. We excluded the participants with concurrent severe medical diseases such as cancer and heart failure. The participants signed informed consent forms, and the protocol was approved by the Institutional Research Board of the hospital. Details of subjects' medical histories such as medication, hospitalization and smoking status were asked in the structural questionnaires. Standardized procedures of physical examination, such as anthropometric measures and blood pressure, were performed $[18,19]$. Blood pressure was measured in the resting position by trained medical assistants. BMI was calculated as weight (in $\mathrm{kg}$ )/square of height (in $\mathrm{m}$ ). Waist circumference was measured midline between the low costal margin and superior posterior iliac crest.

\subsection{Blood sampling and analytic methods}

The procedures of blood sampling and analytic methods are described in previous studies [20,21]. In brief, blood samples were collected from each participant after they had fasting status at least $12 \mathrm{~h}$. Serum total cholesterol levels were measured using the CHOD-PAP method (Boehringer, Mannheim, Germany). HDL-C was measured following precipitation of apolipoprotein B-containing lipoproteins with phosphotungstic acid and magnesium ions (Boehringer, Mannheim, Germany). Triglyceride concentrations were measured by the GPO-DAOS method (Wako Co., Japan). All of the lipids mentioned above were measured using a Hitachi 7450 automated analyzer (Hitachi, Japan). LDL-C concentrations were calculated using the Friedewald formula. All the measures of both samples were carried out in the single hospital. The coefficient of variation was $5 \%$.

\subsection{Criteria of metabolic syndrome}

We defined 10 criteria for metabolic syndrome, grouped into two categories (Table 1). One category included a major component hyperglycemia, insulin resistance in WHO [5], EGIR [6], AACE [7], and central obesity in IDF [8], plus two other components. We excluded patients with diabetes in the criteria of EGIR and AACE. The other category included original ATP III [9] and AHA/NHLBI criteria [10], where metabolic syndrome was defined as more than or equal to three components, considering all components are equal. Besides, we used modified criteria for Asian population in ATP III [14], AHA/NHLBI, and BMI ATP III criteria. For original ATP III criteria, a participant with three of the following was defined as having metabolic syndrome: (1) blood pressure of at least $130 / 85 \mathrm{mmHg}$ or undergoing treatment for hypertension; (2) serum triglyceride of at least $150 \mathrm{mg} / \mathrm{dL}$; (3) HDL cholesterol of $<40 \mathrm{mg} / \mathrm{dL}$ in men and $<50 \mathrm{mg} / \mathrm{dL}$ in women; (4) fasting glucose of $110 \mathrm{mg} / \mathrm{dL}$ or more; (5) central obesity, waist circumference greater than $102 \mathrm{~cm}$ in men and $88 \mathrm{~cm}$ in women. Modified Asian ATP III criteria are the same as the original ATP III except for a waist circumference greater than $90 \mathrm{~cm}$ in men and $80 \mathrm{~cm}$ in women [15]. For evaluating general obesity such as BMI roles in predicting metabolic syndrome, we added BMI as a general obesity component by following ATP III-like criteria. One is to treat BMI $>=27 \mathrm{~kg} / \mathrm{m}^{2}$ only (ATP III/BMI), and another is to treat BMI or waist circumference as proposed by Taiwan Bureau of Health Promotion [22].

\subsection{Statistical analysis}

We performed a three-part analysis. First, we estimated the prevalence rates of various metabolic syndromes, specified by genders. The age standardized prevalence rates and $95 \%$ confidence intervals were also estimated by the world reference population. The age standardized prevalence rates were compared among the 10 criteria-defined rates among the study subjects. Second, we used $\kappa$ statistics to evaluate the agreement and relative importance among different criteria [23]. We specified the metabolic syndrome as binary categories, and estimated the gender-specific $\kappa$ values. We put all 10 criteria together, then separated the 10 criteria into 


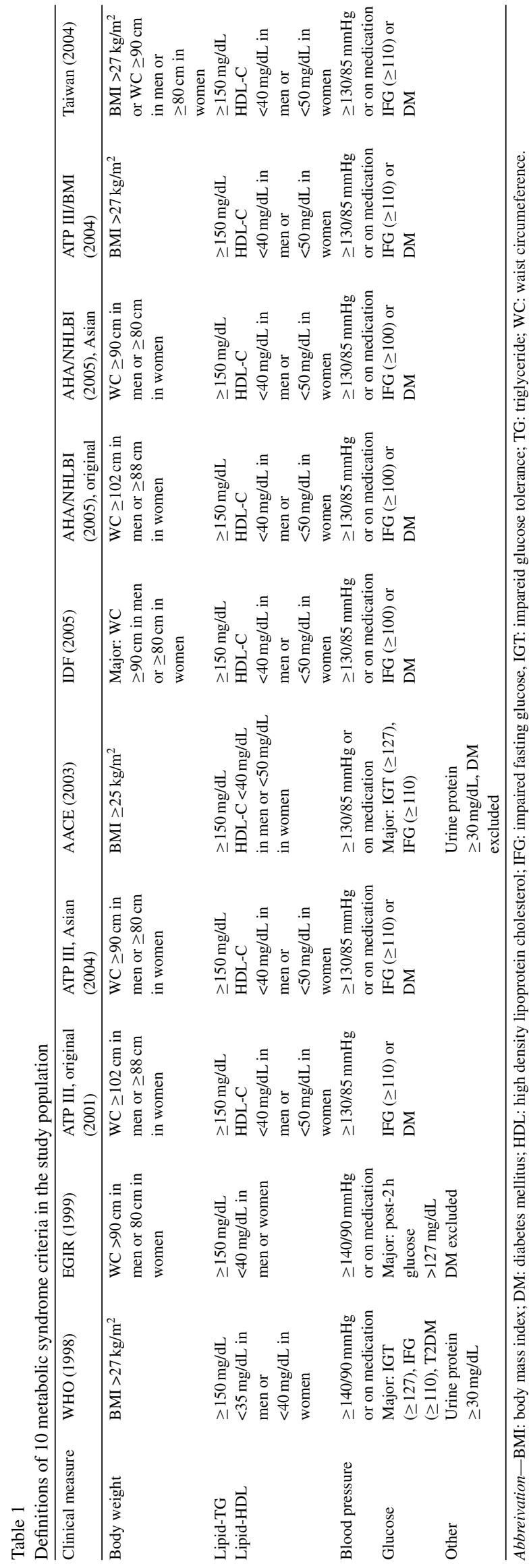

two groups, specified by major components or not. The $\kappa$ statistics estimated the agreement and concordance of classifying all criteria together [24]. Furthermore, we performed the sensitivity analysis to detect the influence of specific criterion by re-calculating the $\kappa$ values by deleting this specific criterion. The percentage of $\kappa$ values was considered as the influence effect of specific criterion.

Third, we performed hierarchical cluster analysis to classify these criteria into several sub-clusters. The goal of cluster analysis is to classify data into homogenous groups or clusters. Before analysis began, all data was considered as separated clusters. Between-groups linkage was used as the method for combining clusters, and its purpose was to minimize the average distance between all pairs of items in which one member of the pair was from each of the items. The distance is the measure of how far apart two objects are, and similarity measure is a measure of closeness. The squared Euclidean distance using standardized data was chosen as the measure of similarity, and the squared Euclidean distance is the sum of the squared differences over all the variables. Cluster analysis was capable of classifying complex components such as dietary constitutes [25], microarray genomic profile data [26] and exploratory factors for metabolic syndrome [17]. It was capable of defining similarity and dissimilarity in various constitutes, and this non-parametric classification technique provided a robust method of grouping and testing for the degree of similarity among studied variables. This method gives hints on the underlying structure and similarity of metabolic syndrome criteria. The dendrogram tree patterns for classifying these variables were used to visualize the underlying cluster and sub-cluster structures.

All statistical analyses were performed using SAS Version 9.1 (SAS Institute, Inc., Cary, NC) and STATA Version 9.1 (Stata Corp., College Station, TX).

\section{Results}

Table 2 showed the basic characteristics of study participants. Men were older, and had higher waist circumference, blood pressure, triglyceride, LDL cholesterol, glucose, and lower BMI and HDL cholesterol concentrations than women. Men had higher prevalence rates of work jobs, married, smoking, drinking habits and body mass index than women. Among the distribution of components of metabolic syndrome, men had higher rates of high blood pressure, triglyceride, and glucose and lower rates of central obesity and low HDL cholesterol than women. The gender specific prevalence rates of metabolic syndrome by different criteria are presented in Table 3. The highest standardized rates were in Asian AHA/NHLBI criterion, up to $25.7 \%$ in men and $21.5 \%$ in women, and the lowest rates were in WHO criterion, $8.8 \%$ in men and $8.0 \%$ in women. Men had higher ageadjusted prevalence rates of metabolic syndrome than women when equal component criteria were used, while women had higher rates when the IDF and EGIR were used. 
Table 2

Basic characteristics in the study participants, specified by genders

\begin{tabular}{|c|c|c|c|c|c|}
\hline & $\operatorname{Men}(I$ & & Women & & $P$ \\
\hline & Mean & S.D. & Mean & S.D. & \\
\hline Age (year) & 52.0 & 12.3 & 50.4 & 12.2 & $<.0001$ \\
\hline BMI $\left(\mathrm{kg} / \mathrm{m}^{2}\right)$ & 24.5 & 3.0 & 22.8 & 3.4 & $<.0001$ \\
\hline $\mathrm{WC}(\mathrm{cm})$ & 84.9 & 8.8 & 79.1 & 9.2 & $<.0001$ \\
\hline Systolic BP (mmHg) & 127.0 & 14.4 & 118.7 & 16.8 & $<.0001$ \\
\hline Diastolic BP (mmHg) & 76.2 & 9.9 & 70.0 & 10.1 & $<.0001$ \\
\hline Total cholesterol (mg/dL) & 201.8 & 35.4 & 203.6 & 38.4 & 0.052 \\
\hline Triglyceride $(\mathrm{mg} / \mathrm{dL})$ & 133.5 & 84.3 & 101.4 & 66.4 & $<.0001$ \\
\hline HDL cholesterol (mg/dL) & 38.8 & 7.7 & 46.3 & 9.5 & $<.0001$ \\
\hline LDL cholesterol (mg/dL) & 119.9 & 31.0 & 112.4 & 32.9 & $<.0001$ \\
\hline Fasting glucose (mg/dL) & 95.5 & 23.5 & 91.1 & 20.6 & $<.0001$ \\
\hline & & $\operatorname{Men}(N=3793), \%$ & & 17), $\%$ & $P$ \\
\hline Occupation & & & & & $<.0001$ \\
\hline No job & & 4.3 & & & \\
\hline Labor work & & 6.2 & & & \\
\hline Non-labor work & & 89.5 & & & \\
\hline Housekeeping & & 0.0 & & & \\
\hline Marry status & & & & & $<.0001$ \\
\hline Single & & 10.6 & & & \\
\hline Married & & 88.5 & & & \\
\hline Divorced or spouse deceased & & 0.9 & & & \\
\hline Smoking (current) & & 20.7 & & & $<.0001$ \\
\hline Alcohol drinking (regular) & & 67.4 & & & $<.0001$ \\
\hline High BP & & 47.5 & & & $<.0001$ \\
\hline High triglyceride & & 28.8 & & & $<.0001$ \\
\hline Low HDL cholesterol & & 60.6 & & & $<.0001$ \\
\hline Central obesity: original & & 2.8 & & & $<.0001$ \\
\hline Central obesity: Asian & & 24.4 & & & $<.0001$ \\
\hline High glucose & & 22.7 & & & $<.0001$ \\
\hline High $\mathrm{BMI} \geq 27$ & & 18.7 & & & $<.0001$ \\
\hline
\end{tabular}

Abbreviation-BMI: body mass index; WC: waist circumference; BP: blood pressure; HDL: high density lipoprotein; LDL: low density lipoprotein.

Agreement among these criteria by $\kappa$ values and the percentage change of $\kappa$ by deleting one criterion are presented in Table 4. For 10 criteria, women had higher $\kappa$ values than men (0.65 versus 0.59$)$, indicating higher consistency in women than in men. The range of percentage change of $\kappa$ was around $1-5 \%$, without large influence from the criteria. We strat- ified the criteria into two groups by types of components: major component or equal component groups. We found that the $\kappa$ values decreased to $0.50-0.54$ in the major component group, and increased to $0.83-0.81$ in the equal component group. Among cases in the major component group, $\kappa$ values increased from 0.50 to 0.77 in men and 0.54 to 0.71

Table 3

Gender specific prevalence rates and corresponding 95\% confidence interval (CI) (\%) of metabolic syndrome by different criteria in the study population

\begin{tabular}{|c|c|c|c|c|c|c|c|c|}
\hline \multirow[t]{2}{*}{ Criteria } & \multicolumn{4}{|l|}{ Men } & \multicolumn{4}{|c|}{ Women } \\
\hline & Crude & Age-standardized & Low $95 \%$ CI & High $95 \%$ CI & Crude & Age-standardized & Low $95 \% \mathrm{CI}$ & High 95\% CI \\
\hline WHO (1998) & 11.2 & 8.8 & 7.9 & 9.7 & 9.1 & 8.0 & 7.1 & 9.0 \\
\hline EGIR (1999) & 11.8 & 9.2 & 8.3 & 10.1 & 12.2 & 10.7 & 9.6 & 11.7 \\
\hline ATP III (2001) original & 18.5 & 15.9 & 14.7 & 17.2 & 15.7 & 13.3 & 12.2 & 14.4 \\
\hline ATP III (2001) Asian & 26.6 & 23.3 & 21.8 & 24.8 & 23.4 & 19.8 & 18.5 & 21.1 \\
\hline AACE (2003) & 16.9 & 13.0 & 12.0 & 14.0 & 16.0 & 13.7 & 12.6 & 14.9 \\
\hline IDF (2005) & 18.1 & 16.2 & 14.9 & 17.6 & 22.4 & 19.0 & 17.7 & 20.3 \\
\hline $\begin{array}{l}\text { AHA, NHLBI (2005) } \\
\text { original }\end{array}$ & 22.2 & 18.8 & 17.5 & 20.2 & 18.0 & 15.1 & 13.9 & 16.2 \\
\hline $\begin{array}{l}\text { AHA, NHLBI (2005) } \\
\text { Asian }\end{array}$ & 29.8 & 25.7 & 24.2 & 27.3 & 25.6 & 21.5 & 20.2 & 22.8 \\
\hline ATPBMI (2004) & 24.0 & 21.7 & 20.2 & 23.2 & 14.8 & 12.4 & 11.3 & 13.5 \\
\hline TAIWAN (2004) & 27.7 & 24.5 & 23.0 & 26.1 & 23.4 & 19.9 & 18.6 & 21.2 \\
\hline
\end{tabular}

World population as a reference population for age standardized rates. 
Table 4

Interrater agreement of different criteria of metabolic syndrome by $\kappa$ values, each cell presenting the $\kappa$ when deleting this criterion

\begin{tabular}{|c|c|c|c|c|}
\hline \multirow[t]{2}{*}{ Criteria } & \multicolumn{2}{|l|}{ Men } & \multicolumn{2}{|c|}{ Women } \\
\hline & $\kappa$ & $\begin{array}{l}\% \text { change of } \kappa \text { by deleting } \\
\text { one criterion }\end{array}$ & $\kappa$ & $\begin{array}{l}\% \text { change of } \kappa \text { by deleting } \\
\text { one criterion }\end{array}$ \\
\hline All 10 criteria & 0.59 & & 0.65 & \\
\hline WHO (1998) & 0.62 & 5.0 & 0.69 & 5.0 \\
\hline EGIR (1999) & 0.63 & 5.9 & 0.68 & 4.8 \\
\hline ATP III (2001) original & 0.58 & 2.1 & 0.64 & 1.7 \\
\hline ATP III (2001) Asian & 0.56 & 5.0 & 0.63 & 3.5 \\
\hline AACE (2003) & 0.62 & 5.0 & 0.68 & 3.9 \\
\hline IDF (2005) & 0.62 & 4.0 & 0.65 & 0.5 \\
\hline AHA, NHLBI (2005) original & 0.58 & 1.9 & 0.64 & 1.8 \\
\hline AHA, NHLBI (2005) Asian & 0.57 & 3.8 & 0.64 & 2.7 \\
\hline ATPBMI (2004) & 0.57 & 3.8 & 0.65 & 0.8 \\
\hline TAIWAN (2004) & 0.57 & 4.5 & 0.63 & 3.5 \\
\hline Major criteria: WHO, EGIR, AACE, IDF & 0.50 & & 0.54 & \\
\hline WHO (1998) & 0.42 & 16.3 & 0.52 & 3.7 \\
\hline EGIR (1999) & 0.42 & 16.3 & 0.47 & 12.4 \\
\hline AACE (2003) & 0.42 & 16.8 & 0.48 & 11.2 \\
\hline IDF (2005) & 0.77 & 54.1 & 0.71 & 31.9 \\
\hline Equal component: ATP III, AHA, Taiwan & 0.83 & & 0.81 & \\
\hline ATP III (2001) original & 0.85 & 2.4 & 0.82 & 0.6 \\
\hline ATP III (2001) Asian & 0.81 & 2.2 & 0.80 & 1.9 \\
\hline AHA, NHLBI (2005) original & 0.85 & 2.2 & 0.82 & 0.4 \\
\hline AHA, NHLBI (2005) Asian & 0.83 & 0.0 & 0.81 & 0.0 \\
\hline ATPBMI (2004) & 0.82 & 0.9 & 0.83 & 2.5 \\
\hline TAIWAN (2004) & 0.81 & 1.7 & 0.80 & 1.9 \\
\hline
\end{tabular}

in women when deleting IDF criterion, and the percentage change of $\kappa$ values was $54.1 \%$ in men and $31.9 \%$ in women, indicating disagreement of IDF with other criteria. The higher percentage change of $\kappa$ values with the sensitivity analyses for the IDF definition in major component groups can be explained by the reason that central obesity is the necessary component in the IDF definition, while the other major components require hyperglycemia or insulin resistance, instead of central obesity. The high $\kappa$ values among equal components (0.80-0.85) demonstrated consistent agreement among ATP,
AHA and BMI components. Also, the $\kappa$ values among equal components were similar between genders.

Hierarchical cluster analysis and dendrograms using average linkage between groups in the study population is shown in Fig. 1. For men, there were two large clusters: major components and equal components. Four sub-clusters were classified and identified clearly. Among them, AACE and IDF together were different from EGIR and WHO sub-clusters, and the modified Asian criteria formed another sub-cluster, different from the original Caucasian waist circumference
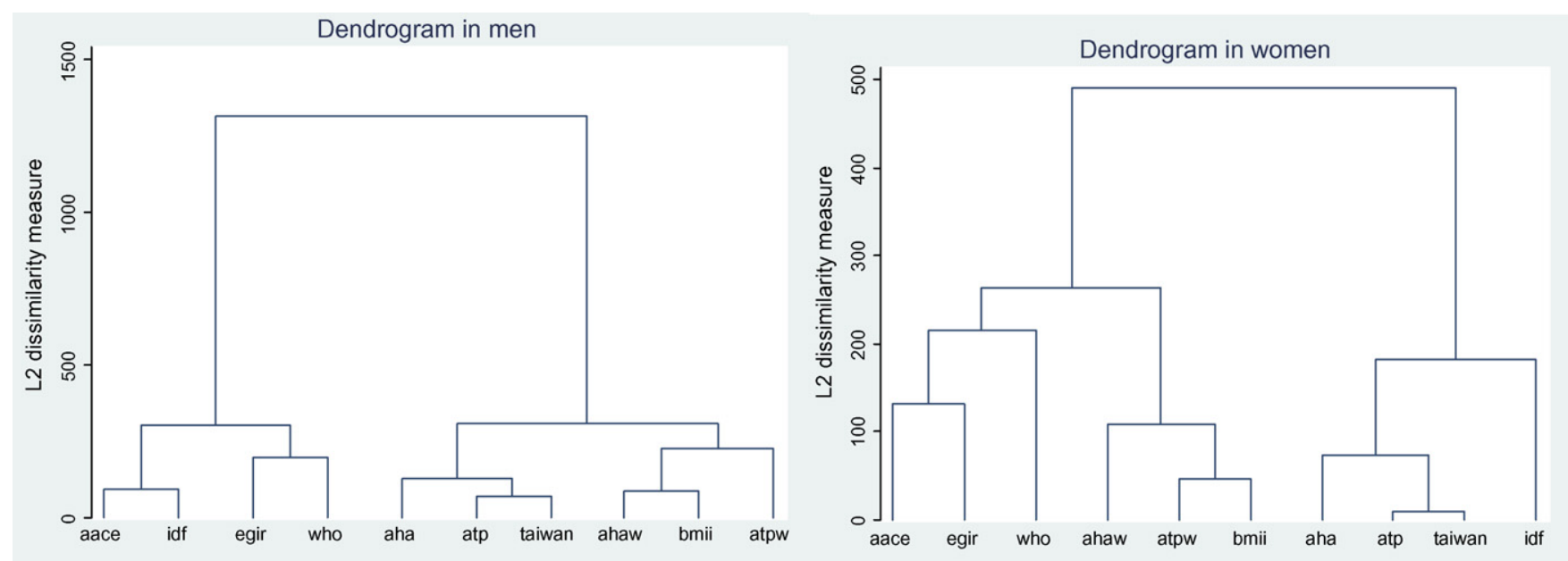

Fig. 1. Hierarchical cluster analysis and dendrograms using average linkage between groups in the study population, specified by men (right) and women (left). 
criteria sub-cluster. The cluster pattern and dendrogram in women were somewhat different from men. Although there was also classification by two clusters in women, the four sub-clusters were different than in men. IDF formed as an independent sub-cluster, separated from other major component criteria, which formed a distinct sub-cluster. In addition, IDF sub-clusters closely related to modified Asian criteria equal component sub-clusters. The cluster and sub-cluster patterns did not change when the cut-off point for BMI changed to $25 \mathrm{~kg} / \mathrm{m}^{2}$ (data not shown).

\section{Discussion}

This is the first report, according to the authors' knowledge, that quantifies the consistency and agreement of various metabolic syndrome models, demonstrating specific model influence on the consistency. We found substantial consistency among these criteria, almost perfect among ATP-like models. Also, we clustered these models into two groups by their similarity. The IDF model was not consistent with other models, and BMI is consistent with waist circumstance components in predicting metabolic syndrome.

It is a complex task summarizing the available criteria for metabolic syndrome up to date. The present time is suitable for performing a critical appraisal of metabolic syndrome [27]. Our contribution is to compare the age-standardized prevalence rates of various metabolic syndrome criteria in the same population. It will be helpful to clinicians and provide public health professionals with additional consideration towards the implications of different criteria.

Compared with other ethnic populations, ethnic Chinese are known to have low rates of diabetes and metabolic syndrome [28], although the burden varies in different areas [29]. Among Chinese, globalization and economic progress has increased much throughout the recent years, and the burdens of obesity and diabetes has taken its toll on public health. Geographical location, economic development and lifestyle patterns play an important role in the prevalence of diabetes and metabolic syndrome. Health promotion programs, such as weight reduction and physical activity, should be implemented for general population, and risk reduction on atherosclerotic burden will be helpful for public health.

Evidence for variation on metabolic syndrome criteria among ethnic Chinese was noted. First, various criteria of metabolic syndrome elicited differential sensitivity and specificity for incident diabetes among 627 high-risk adults in Beijing area [30]. There was heterogeneity for major components criteria: AACE had the highest sensitivity but lowest specificity, and EGIR had the lowest sensitivity but highest specificity for incident diabetes among ethnic Chinese. Second, Wang et al. demonstrated AACE-defined metabolic syndrome had the highest relative risk to predict incident diabetes in the 5-year follow-up period [31]. They found that WHO, EGIR, AACE, IDF and AHA criteria were not predictors of incident $\mathrm{CHD}$ events, partly due to missing important components in these criteria. Our prospective cohort data demonstrated ATP III criteria had the significant predictor for CHD and stroke events [32]. Further investigation on the heterogeneity of various metabolic syndrome criteria is necessary.

The fact of differences in men and women in terms of metabolic syndrome criteria implied that gender difference on metabolic syndrome burdens. The phenomenon was complicated when age and metabolic syndrome components were considered. For example, IDF criteria did not match to other criteria in our study, and the results were compatible with Japanese population [33,34]. Furthermore, elder women were the highest prevalent rates, indicating that menopause might play an important factor for insulin resistance. Overall men had biological susceptibility for atherosclerosis, and the gender difference decreased among older groups [35]. We stratified the study participants into several subclusters, which had rather homogenous patterns. Among men, the patterns of sub-clusters were compatible with original grouping, i.e. major components or equal components. But women's pattern was rather complicated, with IDF criterion merged with Asian ATP criteria. Among 3508 adults in the French communities, increased body weight, waist circumference and low HDL cholesterol elicited more contribution for metabolic syndrome in women than in men. Men's blood pressures were significantly more important contributors than women's blood pressure [36]. The discrepancy of atherosclerotic risk factor between genders should be taken into consideration in clinical care and public health prevention programs. We found that higher percentage change in $\kappa$ values for the IDF definition in the major component groups, but not when the 10 criteria are evaluated together. The reason was that the IDF definition requires the presence of central obesity, while the other major component definitions require hyperglycemia/insulin resistance. We hypothesize that the difference in waist circumference cut-off point is responsible for the lack of consistency among the Chinese population. From the routine health examination data, the proposed cutoff $85 \mathrm{~cm}$ in men and $80 \mathrm{~cm}$ in women for waist circumference criteria were proposed for diagnosis of metabolic syndrome among Japanese population, which had the optimal predictive ability for other risk factors [37].

We investigated different influences of BMI or waist circumference component for obesity criteria. General obesity indicated by high BMI values, were strongly associated with risky cardiovascular biomarkers in western countries [35]. Also, BMI was proven as good criteria for screening Japanese population for metabolic syndrome [33], and the national survey data in Taiwan has demonstrated a significant relationship between BMI and waist circumference [38]. In general survey in adult Taiwanese, general obesity was as important as central obesity for ischemic stroke [39]. We considered that BMI, as a general obesity marker, was still important for cardiovascular disease risk.

The limitations of this study are as follows: First, the recruitment strategy of the study population was from health 
examination program from one tertiary hospital, and the participants had a higher socioeconomic status than the general community population. The socioeconomic levels of our study samples were high, with $74 \%$ above a college education and $71 \%$ with business or other official work. The extrapolation of the results to the general population should be taken into careful consideration. Second, the $\kappa$ statistics, dendrograms and cluster analysis did not provide formal test statistics for significant hypothesis testing. Therefore, the study results should be considered as exploratory and hypothesis generating, not hypothesis testing. Also, the $\kappa$ statistics treats all criteria symmetrically, and it might not be applicable when one or more of these criteria are viewed as a standard.

In conclusion, there was substantial agreement and grouping of metabolic syndrome models among the ethnic Chinese population. Prospective studies should be planned to investigate the impact on cardiovascular disease incidence.

\section{Acknowledgments}

We thank the cardiologists at National Taiwan University Hospital for their assistance in this study. This study was supported by grants from the National Science Council (NSC 93-2314-B-002-218, NSC 94-2314-B-002-290) in Taiwan.

\section{References}

[1] Eckel RH, Grundy SM, Zimmet PZ. The metabolic syndrome. Lancet 2005;365:1415-28.

[2] Ford ES, Giles WH, Dietz WH. Prevalence of the metabolic syndrome among US adults: findings from the third National Health and Nutrition Examination Survey. JAMA 2002;287:356-9.

[3] Hu G, Qiao Q, Tuomilehto J, et al. Prevalence of the metabolic syndrome and its relation to all-cause and cardiovascular mortality in non-diabetic European men and women. Arch Intern Med 2004;164:1066-76.

[4] Wallenfeldt K, Hulthe J, Fagerberg B. The metabolic syndrome in middle-aged men according to different definitions and related changes in carotid artery intima-media thickness (IMT) during 3 years of followup. J Intern Med 2005;258:28-37.

[5] Alberti KG, Zimmet PZ. Definition, diagnosis and classification of diabetes mellitus and its complications. Part 1. diagnosis and classification of diabetes mellitus provisional report of a WHO consultation. Diabet Med 1998;15:539-53.

[6] Balkau B, Charles MA. Comment on the provisional report from the WHO consultation. European Group for the Study of Insulin Resistance (EGIR). Diabet Med 1999;16:442-3.

[7] Einhorn D, Reaven GM, Cobin RH, et al. American College of Endocrinology position statement on the insulin resistance syndrome. Endocr Pract 2003;9:237-52.

[8] The IDF consensus group. The IDF consensus worldwide definition of the metabolic syndrome. http://www idf org/webdata/docs/ MetSyndrome_FINAL pdf, 2005.

[9] Third Report of the National Cholesterol Education Program (NCEP) Expert Panel on Detection, Evaluation, and Treatment of High Blood Cholesterol in Adults (Adult Treatment Panel III) final report. Circulation 2002; 106:3143-421.

[10] Grundy SM, Cleeman JI, Daniels SR, et al. Diagnosis and management of the metabolic syndrome: an American Heart Association/National
Heart, Lung, and Blood Institute Scientific Statement. Circulation 2005;112:2735-52.

[11] Ford ES, Mokdad AH, Giles WH. Trends in waist circumference among U.S. adults. Obes Res 2003;11:1223-31.

[12] Reaven GM. The metabolic syndrome: requiescat in pace. Clin Chem 2005;51:931-8.

[13] Grundy SM. Point: the metabolic syndrome still lives. Clin Chem 2005;51:1352-4.

[14] Ko GT, Cockram CS, Chow CC, et al. High prevalence of metabolic syndrome in Hong Kong Chinese-comparison of three diagnostic criteria. Diabet Res Clin Pract 2005;69:160-8.

[15] Tan CE, Ma S, Wai D, et al. Can we apply the National Cholesterol Education Program Adult Treatment Panel definition of the metabolic syndrome to Asians? Diabet Care 2004;27:1182-6.

[16] Austin MA, Edwards KL, McNeely MJ, et al. Heritability of multivariate factors of the metabolic syndrome in non-diabetic Japanese mericans. Diabetes 2004;53:1166-9.

[17] Girman CJ, Dekker JM, Rhodes T, et al. An exploratory analysis of criteria for the metabolic syndrome and its prediction of longterm cardiovascular outcomes: the Hoorn study. Am J Epidemiol 2005; 162:438-47.

[18] Chien KL, Yang CY, Lee YT. Major gene effects in systolic and diastolic blood pressure in the families receiving health examination in Taiwan. J Hypertens 2003;21:1-7.

[19] Chien KL, Hsu HC, Chao CL, et al. Interaction of obesity, metabolic syndrome and Framingham risk on steatohepatitis among healthy Taiwanese: population-based nested case-control study. Cardiovasc Diabetol 2006;5:12.

[20] Chien KL, Hsu HC, Su TC, Lee YT. Consistency in genetic inheritance mode and heritability patterns of triglyceride vs. high density lipoprotein cholesterol ratio in two Taiwanese family samples. BMC J Genet 2003;4:7-16.

[21] Chien KL, Hsu HC, Chen MF, Lee YT. Association of C-reactive protein, smoking and metabolic syndrome among the health check-up population. Acta Cardiol Sin 2005;21:98-104.

[22] Chen TH, Chiu YH, Luh DL, et al. Community-based multiple screening model: design, implementation, and analysis of 42,387 participants. Cancer 2004;100:1734-43.

[23] Landis JR, Koch GG. The measurement of observer agreement for categorical data. Biometrics 1977;33:159-74.

[24] Fleiss JL, Levin B, Paik MC. Statistical methods for rates and proportions. 3rd ed. Hoboken, NJ: John Wileys \& Sons, Inc.; 2003.

[25] Akbay A, Elhan A, Ozcan C, Demirtas S. Hierarchical cluster analysis as an approach for systematic grouping of diet constituents on basis of fatty acid, energy and cholesterol content: application on consumable lamb products. Med Hypoth 2000;55:147-54.

[26] Bittner M, Meltzer P, Chen Y, et al. Molecular classification of cutaneous malignant melanoma by gene expression profiling. Nature 2000;406:536-40.

[27] Kahn R, Buse J, Ferrannini E, Stern M. The metabolic syndrome-time for a critical appraisal: joint statement from the American Diabetes Association and the European Association for the Study of Diabetes. Diabet Care 2005;28:2289-304.

[28] He Y, Jiang B, Wang J, et al. Prevalence of the metabolic syndrome and its relation to cardiovascular disease in an elderly Chinese population. J Am Coll Cardiol 2006;47:1588-94.

[29] Gu D, Reynolds K, Wu X, et al. Prevalence of the metabolic syndrome and overweight among adults in China. Lancet 2005;365: $1398-405$.

[30] Wang JJ, Hu G, Miettinen ME, Tuomilehto J. The metabolic syndrome and incident diabetes: assessment of four suggested definitions of the metabolic syndrome in a Chinese population with high post-prandial glucose. Horm Metab Res 2004;36:708-15.

[31] Wang JJ, Li HB, Kinnunen L, et al. How well does the metabolic syndrome defined by five definitions predict incident diabetes and incident coronary heart disease in a Chinese population? Atherosclerosis, published online 26 May 2006. 
[32] Chien KL, Hsu HC, Sung FC, et al. Metabolic syndrome as a risk factor for coronary heart disease and stroke: an 11-year prospective cohort in Taiwan community, Atherosclerosis, published online 18 September 2006.

[33] Anuurad E, Shiwaku K, Nogi A, et al. The new BMI criteria for Asians by the regional office for the western pacific region of WHO are suitable for screening of overweight to prevent metabolic syndrome in elder Japanese workers. J Occup Health 2003;45:335-43.

[34] Miyaki K, Hara A, Naito M, et al. Two new criteria of the metabolic syndrome: prevalence and the association with brachial-ankle pulse wave velocity in Japanese male workers. J Occup Health 2006;48:134-40.

[35] Mora S, Lee IM, Buring JE, Ridker PM. Association of physical activity and body mass index with novel and traditional cardiovascular biomarkers in women. JAMA 2006;295:1412-9.
[36] Dallongeville J, Cottel D, Arveiler D, et al. The association of metabolic disorders with the metabolic syndrome is different in men and women. Ann Nutr Metab 2004;48:43-50.

[37] Hara K, Matsushita Y, Horikoshi M, et al. A proposal for the cutoff point of waist circumference for the diagnosis of metabolic syndrome in the Japanese population. Diabet Care 2006;29: 1123-4.

[38] Pan WH, Flegal KM, Chang HY, et al. Body mass index and obesityrelated metabolic disorders in Taiwanese and US whites and blacks: implications for definitions of overweight and obesity for Asians. Am J Clin Nutr 2004;79:31-9.

[39] Chen HJ, Bai $\mathrm{CH}$, Yeh WT, et al. Influence of metabolic syndrome and general obesity on the risk of ischemic stroke. Stroke 2006;37: $1060-4$. 